\title{
The role of IT in energy systems: the digital revolution as part of the problem or part of the solution
}

\author{
F. Kupzog OVE, IEEE(D, R. King, M. Stefan
}

\begin{abstract}
The architectural design of our energy systems dates back to a time without information technology (IT). Over time, IT was applied where it increased efficiency and safety. About 12 years ago, the Smart Grid era began. In the meantime, we talk about digitalization. Electrical energy systems require embedded systems, Internet of Things, computation clusters and data analytics. However, IT also has another role in the energy system, namely that of a substantial consumer. Crypto currencies and data centers are on the rise. We analyze impacts on energy demand and discuss risks and chances of this development.
\end{abstract}

Keywords: ICT energy demand; electric energy systems; blockchain

Die Rolle von IT im Energiesystem: die digitale Revolution als Teil des Problems und Teil der Lösung.

Die Architektur unserer Energieversorgungssysteme stammt aus einer Zeit vor dem Einsatz von Informationstechnologie (IT). Der Einsatz von IT fand zuerst dort statt, wo Effizienz und Sicherheit verbessert werden konnten. Vor ca. zwölf Jahren brach das Zeitalter der Smart Grids an. Inzwischen sprechen wir von Digitalisierung; und Embedded Systems, Internet of Things, Rechencluster und Data Analytics sind aus dem elektrischen Energiesystem nicht mehr wegzudenken. Doch IT nimmt auch eine zweite Rolle im Energiesystem ein: die als Energieverbraucher. Kryptowährungen und Datencenter verzeichnen große Wachstumsraten. Welche Auswirkungen hat dies auf den Energieverbrauch und welche Risiken bzw. Chancen ergeben sich daraus?

Schlüsselwörter: Energieverbrauch IKT; elektrisches Energieversorgungssystem; Blockchain

Received July 3, 2020, accepted July 23, 2020, published online July 30, 2020

(c) The Author(s) 2020

\section{Introduction}

De-carbonization through digitalization - this is an essential approach followed in many energy-relevant areas such as energy provision, industrial processes and mobility. But the worldwide digital revolution also has its own growing share of energy consumption and greenhouse gas emissions consequently. But how concretely can energy consumption and/or greenhouse gas emission be reduced by digitalization? And what will happen with the growing energy demand of IT systems? The fast-growing energy demand of crypto currencies that exceed the total power demand of whole countries with increasing size is still in mind. Similar technologies are strong candidates to be applied in energy trading - will this be counterproductive? This article takes a look at IT in energy and also energy in IT.

\section{Energy in IT systems}

In the design of IT systems, power consumption has always played an important role. Not primarily for energy cost or green reasons, but because in highly integrated digital circuits significant amounts of waste heat power densities occur and temperatures have to be kept in safe bounds. Power densities of 50-75 W per square centimeter chip area can easily occur in computer processors [1]. The prime drivers for energy consumption of digital circuits can be distinguished in static and dynamic effects. Dynamic effects stem from the short time span in which logical states change from zero to one or vice versa. Gate capacities must be charged or discharged in this time, and the power dissipation is data dependent. The static effect has increased with smaller and smaller integration sizes. As isolation layers became thinner, leakage currents increased. Reduction of operation voltage, dynamic clock frequencies, and switching off unused logical blocks are typical strategies to reduce power consumption in digital circuits.

There are considerable aggregation effects on micro and macro scale. For a single chip, Gordon Moore predicted already in 1965, that the number of components on a single integrated circuit would double every year [2]. This prediction became known as "Moores Law" and proved to be correct until today - an end of this trend will be expected in 2025 [3]. Every component (typically transistors) contribute to the power demand of the integrated circuit. On the macro level, data centers come into play, where availability of low cost and highly available electric energy is an important site selection factor. Finally, the world-wide energy consumption of IT systems, including data centers, personal computers, networking infrastructure etc., has reached significant figures over the last years.

\subsection{Data center energy demand}

The contribution of data centers to the worldwide greenhouse gas emissions reached $2 \%$ of the global emissions in 2017, equally large as the aviation sector emissions [4]. Increased use of data centers is

Kupzog, Friederich, AlT Austrian Institute of Technology GmbH, Giefinggasse 4, A-1210 Wien, Austria (E-mail: friederich.kupzog@ait.ac.at); King, Ross, AIT Austrian Institute of Technology GmbH, Giefinggasse 4, A-1210 Wien, Austria; Stefan, Mark, AlT Austrian Institute of Technology GmbH, Giefinggasse 4, A-1210 Wien, Austria 
more than evident. The amount of Internet traffic has tippled within the last three years (IEA, 2018), and the worldwide data center capacity is expected to double from 2016 to 2021 [5]. Reasons for this increase can be experienced by each of us. The technical and societal development of online services, the massive growth in cloud services, which do typically not replace local computation but provide additional services such as social media, trade platforms, mass storage and many others.

With these figures in mind, a strong impact on global data center energy demand growth could be expected. Only very few studies focus on global data center energy demand, since there is a lack of bottom-up data for such an analysis. Studies from 2015, such as Avgerinou et al., assume an exponentially growth in energy demand of data centers (see Fig. 1). However, the actual development has turned out very different, according to [6] or [7] (Fig. 1). The growth between 2010 and 2020 was only in the range of a few percent. With this, the share of data centers in global electricity consumption has stayed at around $1 \%$ in the last decade (IEA, 2018 and [8]).

The reason for this very moderate demand development is that the technological structure of data centers worldwide has significantly changed. The number of data centers has increased, but they are more efficient and larger compared to the traditional asset base. Existing data centers have often been updated to increase their efficiency. While in 2010, servers consumed as much as data center infrastructure (both around $90 \mathrm{TWh} / \mathrm{year}$ ), server demand has increased with more data centers installed in 2018, but infrastructure demand went down to $50 \mathrm{TWh} / \mathrm{year}$, which is a significant efficiency gain [7]. A key measure is to target the cooling demand, reduce need for active cooling and increase operation temperatures [4].

Arguably, looking at data centers only is not grasping the full energy demand of ICT. More distributed computing infrastructure, such as handheld devices, personal computers, automation equipment and networking infrastructure would also need to be considered for a full picture. One particular ICT application, which often comes with dedicated computational hardware in form of arrays of graphics processors, and therefore only partly is accounted for in the data center scope, is Blockchain mining.

\subsection{Blockchain technology evolution}

Over the past five years, Blockchains have been discussed very heavily not only in technical circles, but in popular culture and media as well. One reason for this is the success of Bitcoin, a virtual currency based on Blockchain technologies that has been on-line since 2009, proving the feasibility and robustness of the concept. Less-deserved reasons for this hype however are the asset bubbles that have been inflated by numerous cryptocurrencies, including Bitcoin, which have nothing to do with the fundamental usefulness of Blockchain technologies.

There are many different implementations of Blockchains, which are characterized primarily by whether they are intended for public (or open or permissionless) or private (or closed or permissioned) networks, by which Consensus Protocol they use, and by whether and how they support Smart Contracts. Both Bitcoin and Ethereum are examples of public Blockchains supported by the Nakamoto consensus protocol, more commonly referred to as "proof of work" (PoW). Ethereum is distinguished by its additional support of "Smart Contracts", in reality a Turing-complete programming language that can be integrated with the validation of transactions in that network.

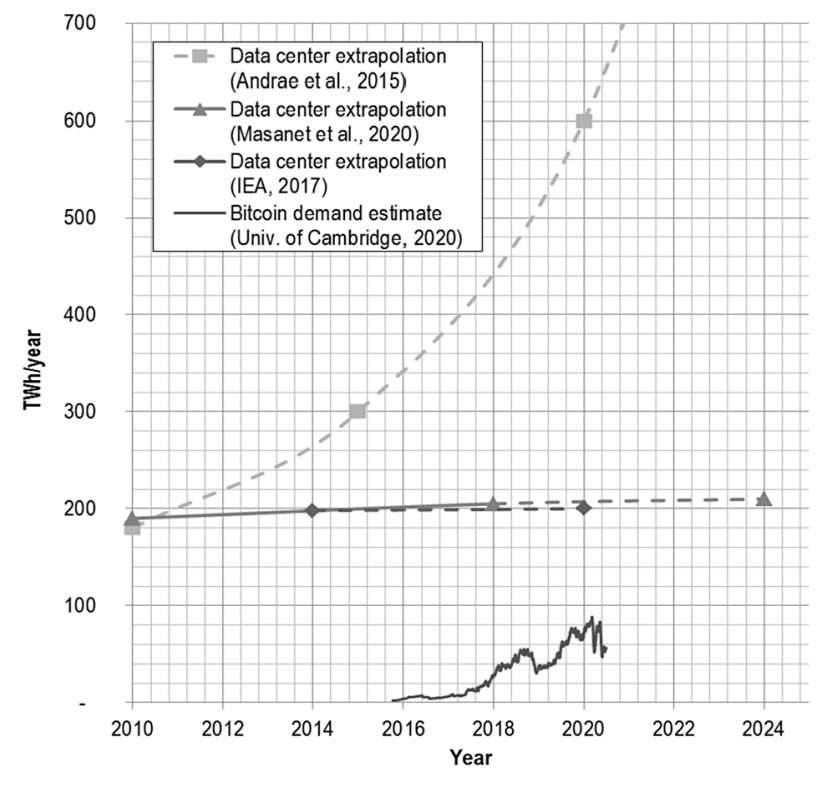

Fig. 1. Comparison of worldwide data center energy demand scenarios and estimated Bitcoin network demand

PoW consensus mechanisms are very energy-inefficient, relying on a computationally intensive guessing game to produce hash values of transaction blocks that have specific characteristics. Whichever participating node wins the game is allowed to publish the next valid transaction block in the Blockchain. Estimates suggest that the Bitcoin network expends around 56 TWh/year [9] carrying out the calculations for the consensus mechanism. This comes in the range of Austria's annual electricity demand. Based on figures in [4], this results in approximately $0.5 \%$ of global greenhouse gas emissions. Clearly this type of consensus is not environmentally friendly or sustainable. Figure 1 depicts an estimate of the Bitcoin system demand based on mining data, and brings this into context of worldwide data center demand (Bitcoin mining is often done on dedicated hardware). The large dip in the curve corresponds to the bitcoin crash at the end of 2018.

Less energy is required with the so-called "proof of stake" (PoS) approach, in which the probability of stakeholder being chosen to publish a block is proportional to his stake as recorded in the ledger itself. Several PoS protocols embracing this idea have been shown to achieve provable security guarantees in various models [10] and [11]. PoS however has the disadvantage of concentrating decisionmaking power in a Blockchain network. The Ethereum community is working on a shift to this mechanism.

Another approach is to abandon the public Blockchain and focus on private or permissioned networks. Consensus in such networks is an example of the Byzantine General Problem, as described in [12]. Ripple and Tendermint are examples of implementations that rely on variations of Practical Byzantine Fault Tolerance [13] as their consensus mechanism. While these approaches are far more economical in terms of energy consumption, they require a large volume of network messaging between the participating consensus nodes, which can lead to scalability problems in large private networks.

\section{IT in energy systems}

As in any other domain, energy systems without information and communication technologies would be unimaginable today. IT is a key enabler for replacing fossil-based power generation with renew- 
ables [14]. It helps to make energy consumption processes in industry more efficient [15]. And it helps to efficiently run our electric power grids

Nevertheless, the original designers of our continent-spanning power system did have no microprocessors, glass fibers, satellite communication, or time synchronization available. Consequently, technical communication in the power transmission system is organized using a physical broadcast parameter: the grid frequency. Balancing supply and demand in any time instance is done based on power-frequency droop control, essentially a distributed proportional control architecture based on the grid frequency as controlled variable [16]. Nevertheless, for planning, operation and analysis of power systems, the use of IT systems is ever increasing. The main application areas of ICT in power systems today are energy tariffing and trading, grid planning, automation and control, grid integration of renewables and electric mobility, energy management, electrical protection, cyber security and many data-based applications such as (predictive) maintenance. In all these areas significant research and development efforts are taking place.

\subsection{Tariffing and trading: from smart meters to flexibility platforms}

While bulk energy trading went through a similar digitalization path like many other trading platforms, including experimentation with Blockchains (see e.g. [17]), new market and tariffing models on smaller scale are often based on Smart Meters. This technology that is currently rolled out in European countries using different IT architectures and approaches aims to increase end-use energy efficiency, allows load profile based tariffing schemes and is often also seen as the key hardware for digital distribution grid operation. The rollout of Smart Meters comes with many more than only technical challenges (see e.g. [18] for the Dutch case). In case of Austria, the roll out is still ongoing, initial estimates for efficiency increase were $3,5 \%$ but might not be met in practice as data from the Netherlands, UK and Switzerland suggest values in the range of $1 \%$ to $3 \%$ [19]. However, without Smart Meters, only sparse operational data is available from electrical distribution grids. The introduction of Smart Meters significantly increases the data availability for electricity end use and grid loading situations, opening many options for data analytics.

A currently very active field of IT application in power systems is activation of flexibility, i.e. the intentional change of power generation or consumption to reduce peak power or better match demand and supply. While the necessity to make use of generation and load flexibility for system balancing in the presence of large amounts of renewables is known for long, only in recent years implementation efforts have ramped up in Europe. From an IT perspective, this is primarily a question of system architecture and interface design (see e.g. [20]). Figure 2 gives an impression of what kind of information links are in place today or currently evolving. All this happens in a multi-stakeholder environment, with energy providers, grid operators, "prosumers" (energy customers who also feed renewable energy back into the grid), and aggregators. Aggregators, or "virtual power plants" (see e.g. [21]), aggregate larger numbers of smaller units of different kinds, such as renewable energy sources, loads and flexibilities, and take advantage of better portfolio management. Only recently, also manufacturers enter this arena with their original manufacturer equipment clouds (OEM clouds) that pool devices of a certain manufacturer. The Solar Web cloud system for instance pools more than a Gigawatt of distributed photovoltaic generation units [22]. Such manufacturer-specific pools can operate device flexibilities based on different motives than a private energy management

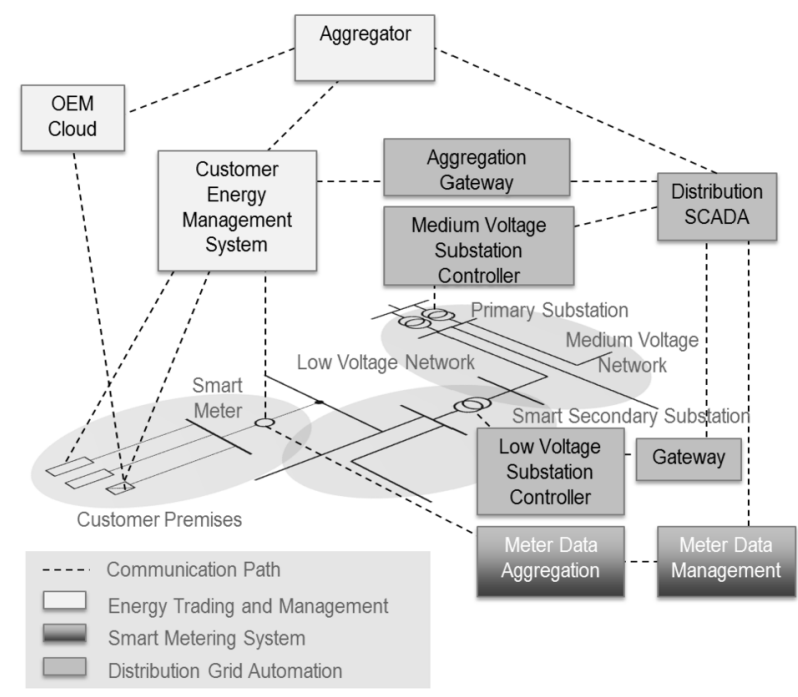

Fig. 2. Landscape of IT Interfaces in power distribution

might do, e.g. based on pricing of an ancillary services market, while the local system would seek to maximise local energy self-sufficiency.

Once technology is in place to activate flexibilities, it is only a small step towards flexibility coordination or even flexibility trading platforms for congestion management in distribution and/or transmission grids (see e.g. [23]). Local flexibility markets are researched and discussed for several years [24]. Prototypical implementations are currently on the way in many places, e.g. in the frame of the German "SINTEG - Schaufenster für intelligente Energie" program, where different underlying principles and architectures are tested, including Blockchain. Also the interaction between transmission and distribution system operators is to a large extend a flexibility coordination problem [25]. While flexibility markets are seen advantageous in terms of formation of prices, market liquidity in localized markets can be an issue as well as the fact that often the unit that causes congestion is also able to solve the problem.

\subsection{Renewable energy: from direct grid connection to energy} communities

The approach how renewable energies are integrated in the power system has changed over time. Initial connections of small wind and photovoltaic units were done on a "fit and forget" basis [26]. With rising level of distributed generation in distribution grids, more advanced methods became necessary, since either voltage or current constraints of the existing infrastructure were - at least nominally met. And the role of IT is getting more and more important. Using appropriate control schemes such as voltage-based reactive power control and other control techniques, the hosting capacity of existing distribution grids can be increased by 100 to $200 \%$ over the as is value [27]. Similar approaches can be used with charging stations for electrical vehicles with appropriate charging hardware [28].

From a system perspective however, it makes sense to balance local renewable generation as close to the source with local loads. Energy communities have received increased attention in recent years and will be an essential part of the future energy system, since they define the paradigm change from directly grid-connected renewables to grid-connected communities that run local optimizations and balancing. This role is confirmed by the European Commission within the Clean Energy for All Europeans Package and formally acknowledges two different types of energy communities, namely the 
Renewable Energy Community and the Citizen Energy Community [29].

Energy communities will provide chances for prosumers to store their surplus energy within storage systems (e.g., within community battery storage) for later use and thus, to increase their selfconsumption. On the other hand, additional surplus can be shared within the community or can be sold to other community members, which will increase the community self-consumption. Energy management systems for communities can be implemented to support these sharing concepts and to create economic benefits for the participating customers. This is another potential use case for Blockchain technology. The Austrian research project Blockchain Grid implemented such a concept within a small renewable energy community in Styria and reveals cost savings for residential customers in the range of $10 \%$ of the total energy costs including grid fee and taxes [30].

\section{Conclusion and outlook}

So, is IT finally part of the problem or part of the solution in terms of de-carbonization of the energy system? As shown, it is both. On one hand, it is clearly a demand driver, but for technical, structural and finally also economic reasons, the often postulated unrestricted growth of IT energy demand is not observable. As integration density with today's semiconductor technologies will come to a limit probably in the next decade, also on the very base of technical development we will see a diversification of strategies. Designers will spend more efforts in reducing the number of transistors needed for a certain function, resulting in more compact and energy efficient designs. This for sure will have an impact on the way how the global ICT energy demand will develop. There is however a lack of bottom-up demand data today, especially given that system boundaries need to be taken into account. Technological alternatives in a neighboring field will also have an impact on energy efficiency: wide band gap semiconductor materials are entering the power electronics market and enable more efficient converter designs (see e.g. [31]).

On the other hand, IT in a magnitude of shapes is a clear enabler for energy efficiency and the shift towards renewable sources of energy. We have looked mostly on electricity here, since decarbonization comes with a shift towards electricity as energy carrier. The electricity grid will play a key role in a future energy system with strongly interlinked, i.e. sector-coupled, energy carriers such as renewable gas and heat. The digitalization of sector interfaces is a challenge for itself, since critical supply infrastructures need to be physically and digitally interlinked in a safe and resilient way.

Publisher's Note Springer Nature remains neutral with regard to jurisdictional claims in published maps and institutional affiliations.

Open Access Dieser Artikel wird unter der Creative Commons Namensnennung 4.0 International Lizenz veröffentlicht, welche die Nutzung, Vervielfältigung, Bearbeitung, Verbreitung und Wiedergabe in jeglichem Medium und Format erlaubt, sofern Sie den/die ursprünglichen Autor(en) und die Quelle ordnungsgemäß nennen, einen Link zur Creative Commons Lizenz beifügen und angeben, ob Änderungen vorgenommen wurden. Die in diesem Artikel enthaltenen Bilder und sonstiges Drittmaterial unterliegen ebenfalls der genannten Creative Commons Lizenz, sofern sich aus der Abbildungslegende nichts anderes ergibt. Sofern das betreffende Material nicht unter der genannten Creative Commons Lizenz steht und die betreffende Handlung nicht nach gesetzlichen Vorschriften erlaubt ist, ist für die oben aufgeführten Weiterverwendungen des Materials die Einwilligung des jeweiligen Rechteinhabers einzuholen. Weitere Details zur Lizenz entnehmen Sie bitte der Lizenzinformation auf http://creativecommons.org/licenses/by/4.0/deed.de.

\section{References}

1. Flynn, D., Aitken, R., Gibbons, A., Shi, K. (2007): Low power methodology manual: for system-on-chip design. Berlin: Springer.

2. Schaller, R. R. (1997): Moore's law: past, present and future. IEEE Spectr., 34(6), 5259.

3. Cross, T. (2016): After Moore's Law. The Economist Technology Quarterly. Retrieved 2016-03-13.

4. Avgerinou, M., Bertoldi, P., Castellazzi, L. (2017): Trends in data centre energy consumption under the European code of conduct for data centre energy efficiency. Energies, 10(10), 1470

5. Cisco (2018): Cisco Global Cloud Index: forecast and methodology. 2016-2021 white paper, Cisco, document 1513879861264127

6. International Energy Agency (2017): Digitalization \& Energy

7. Masanet, E., Shehabi, A., Lei, N., Smith, S., Koomey, J. (2020): Recalibrating global data center energy-use estimates. Science, 367(6481), 984-986.

8. International Energy Agency (2020): Data and statistics, electricity consumption world, https://www.iea.org/data-and-statistics/?country=WORLD\&fuel=Energy $\% 20$ consumption\&indicator=Electricity\%20consumption. Accessed on June 26th, 2020.

9. Univ. of Cambridge (2020): Cambridge bitcoin electricity consumption index. https://cbeci.org/. Accessed 1.7.2020.

10. Bentov, I., Pass, R., Shi, E. (2016): Snow white: provably secure proofs of stake. Cryptology ePrint archive, report 2016/919. http://eprint.iacr.org/2016/919.

11. Badertscher, C., Gazi, P., Kiayias, A., Russell, A., Zikas, V. (2019): Ouroboros chronos. Permissionless clock synchronization via proof-of-stake. Cryptology ePrint archive, report 2019/838

12. Lamport, L., Shostak, R., Pease, M. (1982): The Byzantine generals problem. ACM Trans. Program. Lang. Syst., 4(3), 382-401.

13. Castro, M., Liskov, B. (1999): Practical Byzantine fault tolerance. In OSDI (Vol. 99, pp. 173-186).

14. Speer, B., Miller, M., Schaffer, W., Gueran, L., Reuter, A., Jang, B., Widegren, K. (2015): Role of smart grids in integrating renewable energy (No. NREL/TP-6A20-63919). National Renewable Energy Lab.(NREL), Golden, CO (United States).

15. Hofmann, R., Halmschlager, B., Knöttner, S., Leitner, B., Pernsteiner, D., Prendl, L., Sejkora, C., Traupmann, A. (2020): Digitalization in industry. Whitepaper. Climate and energy fund of the Austrian Federal Government.

16. Kundur, P. (1994): Power system stability and control (pp. 581-592). New York: McGrawHill.

17. Pichler, M., Meisel, M., Goranovic, A., Leonhartsberger, K., Lettner, G., Chasparis, G., Vallant, H., Marksteiner, S., Bieser, H. (2019): Decentralized energy networks based on blockchain: background, overview and concept discussion. In Business information systems workshops: BIS 2018 international workshops. Revised papers Vol. 339 Berlin, Germany, July 18-20, 2018 (p. 244). Berlin: Springer.

18. Van Aubel, P., Poll, E. (2019): Smart metering in the Netherlands: what, how, and why. Int. J. Electr. Power Energy Syst., 109, 719-725.

19. Rechnungshof Österreich (2019): Bericht des Rechnungshofes, Einführung intelligenter Messgeräte (Smart Meter). Reihe BUND 2019/1.

20. Kupzog, F., Genest, O., Ahmadifar, A., Berthomé, F., Cupelli, M., Kazmi, J., Monti, A. (2018): SGAM-based comparative study of interoperability challenges in european flexibility demonstrators: Methodology and results. In 2018 IEEE 16th International Conference on Industrial Informatics (INDIN) (pp. 692-697). New York: IEEE.

21. Pudjianto, D., Ramsay, C., Strbac, G. (2007): Virtual power plant and system integration of distributed energy resources. IET Renew. Power Gener., 1(1), 10-16.

22. Fronus (2020): Solar web, https://www. solarweb.com/. Accessed 29.6.2020.

23. Morch, A. Z., Siface, D., Gerard, H., Kockar, I. (2019): Market architecture for TSODSO interaction in the context of European regulation. In 2019 16th international conference on the European energy market (EEM) (pp. 1-5). New York: IEEE.

24. Kornrumpf, T., Meese, J., Zdrallek, M., Neusel-Lange, N., Roch, M. (2016): Economic dispatch of flexibility options for Grid services on distribution level. In 2016 power systems computation conference (PSCC) (pp. 1-7). New York: IEEE.

25. Madina, C., Kuusela, P., Rossi, M., Aghaie, H. (2019): Optimised TSO-DSO coordination to integrate renewables in flexibility markets. In 2019 16th international conference on the European energy market (EEM) (pp. 1-6). New York: IEEE.

26. Ochoa, L. F., Dent, C. J., Harrison, G. P. (2009): Distribution network capacity assessment: variable DG and active networks. IEEE Trans. Power Syst., 25(1), 87-95.

27. Le Baut, J., Zehetbauer, P., Kadam, S., Bletterie, B., Hatziargyriou, N., Smith, J., Rylander, M. (2016): Probabilistic evaluation of the hosting capacity in distribution networks. In 2016 IEEE PES innovative smart grid technologies conference Europe (ISGTEurope) (pp. 1-6). New York: IEEE.

28. Kesler, M., Kisacikoglu, M. C., Tolbert, L. M. (2014): Vehicle-to-grid reactive power operation using plug-in electric vehicle bidirectional offboard charger. IEEE Trans. Ind. Electron., 61(12), 6778-6784.

29. Caramizaru, A., Uihlein, A. (2020): Energy communities: an overview of energy and social innovation. Publications office of the European Union. 
30. Stefan, M., Zehetbauer, P., Cejka, S., Zeilinger, F., Taljan, G. (2020): Blockchain-based self-consumption optimization and energy trading in renewable energy communities. CIRED workshop, Berlin, Paper 144.

\section{Authors}

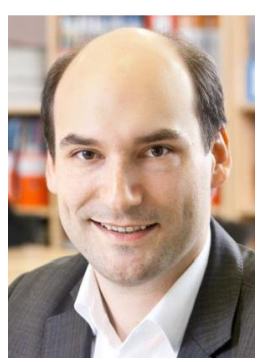

\section{Friederich Kupzog}

is heading the competence unit "Electrical Energy Systems" at AIT Austrian Institute of Technology $\mathrm{GmbH}$. His re- search focuses on power system digitalisation and validation methods for coordination and control applications in a power system con- text. Dr. Kupzog holds lectures in Smart Grid related topics at Vienna University of Technology and other universities and is active in numerous conferences. He was awarded the Austrian Smart Grid Pioneer Award $(2010,2012)$ and the Siemens Inventor of the Year award in 2017.

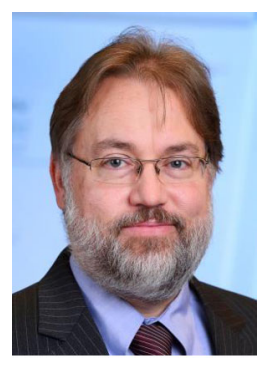

\section{Ross King}

is the head of the competence unit "Data Science \& Artificial Intelligence" within AlT's center for Digital Safety \& Security. He has coordinated numerous large research projects, including BITCRIME, FLORIDA and, most recently, the H2O2O project TITANIUM. His research in recent years has focused on quantitative methods for scalable analysis and has helped to establish for predictive analyt- ics techniques for blockchains.
31. Makoschitz, M., Krischan, K., Bergmann, P., Diaz, A., Brueniger, R. (2020): Wide band gap technology: efficiency potential and application readiness map. $4 \mathrm{E}$ power electronic conversion technology annex (PECTA), IEA 4E PECTA.

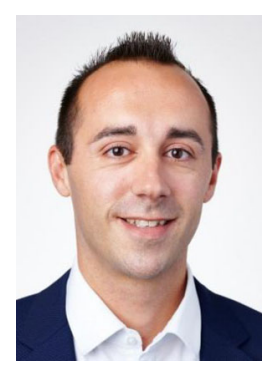

\section{Mark Stefan}

is a Senior Research Engineer and Thematic Coordinator at the research field "Power System Digitalisation" within the competence unit "Electrical Energy Systems" at AIT Austrian Institute of Technology GmbH. He coordinates several research projects in the area of digitalisation and the development of new ICT-based applications for power systems. Mark Stefan studies computer science at the Vienna University of Technology and received his PhD in 2015. 